\title{
Mendelian Homogeneous Family Association of Writer's Cramp
}

\author{
Rohit Verma*1 and Kuljeet Singh Anand ${ }^{2}$ \\ ${ }^{1}$ Department of Psychiatry, All India Institute of Medical Sciences, India \\ ${ }^{2}$ Department of Neurology, Post Graduate Institute of Medical Education and Research, India
}

Received: June 12, 2018; Published: June 19, 2018

*Corresponding author: Rohit Verma, Department of Psychiatry, All India Institute of Medical Sciences, Room No. 4096, 4th Floor, Teaching Block, , Ansari Nagar, New Delhi, India

\section{Abstract}

Available familial, neurophysiologic and imaging evidence suggests that primary adult-onset focal dystonia has a combined genetic and environmental aetiological basis. We report an Indian family which presented writer's cramp in two generations involving three individuals. No such family from India has yet been reported.

Keywords: Writer's cramp; Dystonia; Genetic

\section{Introduction}

Dystonia is a disorder characterized by excessive movements, including sustained involuntary movements, distorted voluntary movements, and abnormal postures. Primary adult-onset dystonia, the most common form of dystonia, has variable clinical expression, often focal onset (blepharospasm, oromandibular dystonia, cervical dystonia, laryngeal dystonia, or arm dystonia), and a limited tendency of spreading to adjacent body regions [1]. Writer's cramp (WC) is a task specific variant of primary focal dystonia shown by involuntary muscle contractions in the arm or hand while writing. It may lead to pain and difficulty in holding a pen, paper destruction and inability to write legibly. Earlier work on WC shifted the causative mechanism from a psychological to physical basis [2]. With the underlying patho physiology in dystonia still unknown, several hypothesis have been put forward - a decrease of inhibition, an impairment in sensory function or an increase of plasticity [3]. Loss of inhibition may cause the excessive movement including abnormally long bursts of electromyography activity, co-contraction of antagonist muscles, and overflow of activity into muscles not intended for the task [3].

Psychophysical studies have revealed evidence of abnormal somatosensory spatial discrimination and temporal discrimination in dystonia patients $[4,5]$. An abnormal plasticity of the motor cortex has been demonstrated using the technique of paired associative stimulation (PAS) suggesting that repetitive activity can lead to dystonia [6]. PAS produces motor learning similar to long-term poten tiation. It produces a larger increase in motor evoked potential in dystonia patients as compared to normal subjects. Not only is the plasticity increased, but there is a failure of its homeostatic property [7]. Homeostatic plasticity is the phenomenon whereby plasticity remains within limits. If, for example, the excitability of the motor cortex is high, then it cannot be driven higher, only lower. This plasticity can be exceeded in dystonia. Sheehy and Marsden grouped WC into three varieties: 'simple cramp' movements abnormal in relation to a single task; 'dystonic cramp' movements abnormal from the outset in relation to more than one task; and 'progressive cramp' abnormal movements which began in relation to a single task and later became abnormal in other tasks [2].

Whereas simple cramps show subtle physical signs similar to other basal ganglia diseases, patients with dystonic cramp are frequently associated with features of segmental and generalized dystonia [2]. Current evidence suggests primary adult-onset focal dystonia to be of multi factorial origin with most probably genetic basis for various clinical forms [1]. We report an Indian family which presented WC in two successive generations involving three individuals - the patient, her father and brother. No such family from India has yet been reported.

\section{Case Report}

The patient Ms. A, a right-handed 28-year-old Indian female, pursuing law course, pre $\neg$ sented with difficulty in writing for two 
years with right hand that adopted an abnormal posture such that it attracted the attention of other persons. The disturbance was accompanied by a feeling of stiffness and intense pain in the thenar region, within seconds of task initiation, along with extension and radial deviation of the wrist and index finger while the fingers bent together clutching the pen. Although there was no micrographic, the pressure on the paper was slightly increased. These symptoms lasted as long as writing continued with varying intensity influenced by the emotional state of the patient. All other manual activities were carried out normally. Currently, she wrote illegibly and that too for not more than 10 seconds. The father of the patient was a 58-yearold right-handed lawyer, experiencing non-progressive severe difficulty in writing for 33 years. The difficulty consisted of abnormal posture of the hand, inability to maintain the pen in correct position, and involuntary extension of the index finger. All these symptoms were present only during writing and drawing. The resulting script was almost illegible, and the difficulty in writing so marked that he has been using a typewriter from the onset of trouble.

The brother of the patient, 26 years old, right-handed, engineer, reported of abnormal writing from 1 year having similar pattern of difficulty in writing with right hand in extension and radial deviation of thumb and index finger with forced flexion of fingers while clutching the pen. The writing eventually terminated due to pain in thenar region or slippage of pen. Currently, he was able to write for 5-6 minutes continuously, outperforming other 2 affected family members. Similar to the other two affected family members, the difficulty in hand and wrist movements was unseen in all tasks except writing. There was no involvement of abnormal movement in any other body part in all three affected family members. While the patient and her brother had not received any specific treatment, the father had tried various medications during the course of illness with no favourable consequence. There was no other past or family history of similar or any other neurological/ psychiatric illness. There was no history of any substance abuse. All the three family members were non-diabetic, normo tensive and vegetarian.

The general physical and systemic examination including neurological was normal. A moderate increase in tone in wrists, a little more marked on the right, with contra lateral activity was noted in all three individuals.

Mini International Neuropsychiatric Interview [8] was insignificant for any psychiatric disorder in all the cases. The haematological and biochemical studies, uric acid, LE phenomenon, RA, ASO, CRP, B12 level, copper, ceruloplasmin, parathormone levels, urine examination, radiographs of the chest and skull, ECG, EEG, EMG, and brain MRI were normal in all the cases. There was no consanguinity between parents of the patient. No similar complaints were reported by the other two siblings (one elder sister and youngest brother) or any other family members (Figure 1).

\section{Writing Test}

All three cases were observed and tested for writing difficulty. It was observed that the right wrist was placed in extension and radial deviation, with its ventral aspect on the table and fingers forced in flexion. While writing, the posture worsened; the pen be- came sustained between thumb, middle and ring fingers and, eventually, escaped. When the attempt to write ceased, all these signs disappeared. The patient, her father and brother took 52, 75 and 30 seconds respectively, on using timed writing (time taken to write the sentence "The quick brown fox jumps over the lazy dog"). Using the Burke-Fahn-Marsden scale [9], the scores for the dystonic effect and for handwrit-ing were both 2 for all of them. The modified Ashworth scale [10] score was 3 and severity score by Jedynak [11] for writing quality was 2 for the patient and her father, while the score was 2 and 2 respectively for the brother. Using a pain analogue scale, it was observed that a few seconds after beginning to write, a pain in the fingers and thenar region appeared, which was scored as 5 and 10 respectively for the patient, 7 and 10 respectively for her father and 4 and 7 respectively for the brother.

\section{Discussion}

To our knowledge this is the first time that an Indian family, with three members of two generations, was described having simple WC according to the criteria of Sheehy and Marsden [2]. Within this family, clinical manifestation was that of an isolated difficulty in hand and wrist movements during writing, which was concealed during all other tasks. Primary focal dystonia is usually sporadic and of late onset ( $>26$ years) [1]. Approximately $8-27 \%$ of late onset probands report having family history of dystonia in at least one first degree relative [12]. Reports of familial presentation in many cases suggest partial genetic origin of primary adult-onset dystonia [1]. But the complexity of the situation is enhanced with reports of families encompassing similar or different dystonia types amongst its members. Our literature search identified reports of eight families with individuals having phenotypic homogeneity of primary mixed-onset dystonia; namely torsion dystonia (two families), focal hand dystonia (four families) and blepharospasm (two families). DYT1 gene was identified in two families with WC $[13,14]$ and DYT7 locus was observed in two families, one with torsion dystonia, and the other with WC $[15,16]$.

While DYT6 was noticed in a family with torsion dystonia [17] no definite loci was found in two families with blepharospasm [18] and one family with WC [19]. DYT6, DYT7 and DYT13 are also implicated in families with focal dystonias having heterogeneous dystonia presentations [20-23]. DYT1 gene gas been also been reported in studies of isolated FHD patients [24]. Other families without any known genetic anomaly have also been described [21]. Previous literature has reported evidence for a possible multi factorial origin for various clinical forms of dystonia but with similar etiological factors, most likely genetic [21]. While a susceptible genetic factor(s) may lead to variable clinical presentations, families with similar dystonia presentation suggest distinct genetic entities, as may be true in our case. With the transmission pattern consistent with either autosomal dominant trait and reduced penetrance or multi factorial inheritance, the aetiological cause is still shady [1]. Researchers suggest that the variable age of onset of diverse clinical types combined with the cross-sectional approach of available family studies lay ground for a possibility that families with apparently homogeneous dystonia may become phenotypically heterogeneous on follow up [25]. 
Currently no specific treatment has shown consistent improvement in patients with WC. This compiled with the deficiency in knowledge and skills for breaking bad news among the physicians, significantly hampers the quality of life in a patient [26]. Our case report describes a family with adult-onset simple writer's cramp favouring a genetic origin of Mendelian homogeneous nature (Fig- ure 1). Our hypothesis is that this case report represents a form of Mendelian trait with influence of multiple factors. Until now specification of gene/loci is missing and the exact cause needs to be presumed. To ascertain information on specific etiology for single form of adult-onset focal dystonia, longitudinal studies with large cohort need be undertaken.

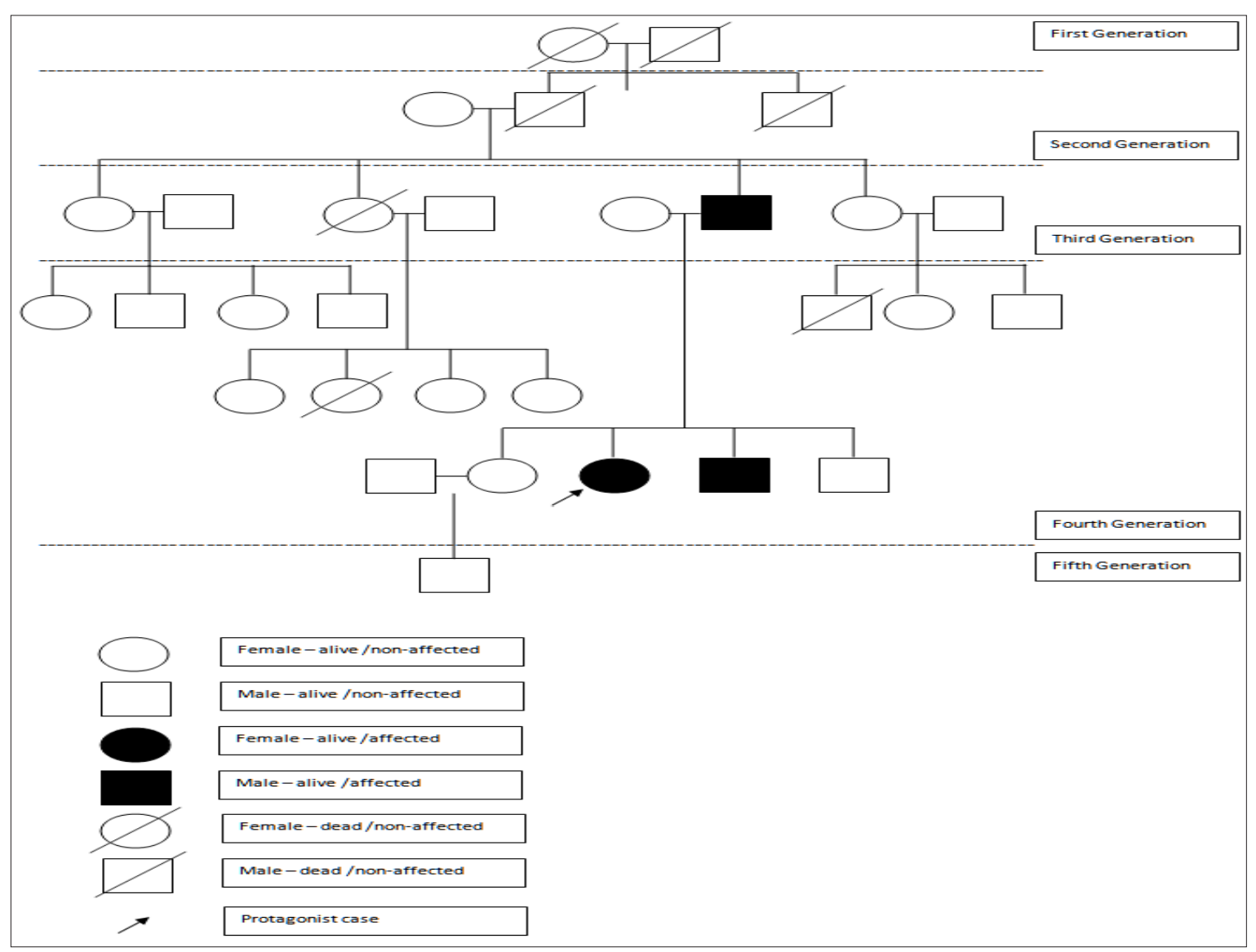

Figure 1: Family Tree.

\section{References}

1. De Carvalho Aguiar PM, Ozelius LJ (2002) Classification and genetics of dystonia. Lancet Neurol 1(5): 316-325.

2. Sheehy MP, Marsden CD (1982) Writers' cramp - a focal dystonia. Brain 105(3): 461-480.

3. Hallett M (2006) Pathophysiology of writer's cramp. Hum Mov Sci 25: 454-463.

4. Bara-Jimenez W, Shelton P, Hallett M (2000) Spatial discrimination is abnormal in focal hand dystonia. Neurology 55(12): 1869-1873.

5. Fiorio M, Tinazzi M, Bertolasi L, Aglioti SM (2003) Temporal processing of visuotactile and tactile stimuli in writer's cramp. Ann Neurol 53(5): 630-635.

6. Quartarone A, Bagnato S, Rizzo V, Siebner HR, Dattola V, et al. (2003) Abnormal associative plasticity of the human motor cortex in writer's cramp. Brain 126(12): 2586-2596.

7. Quartarone A, Rizzo V, Bagnato S, Morgante F, Sant'Angelo A, et al. (2005) Homeostatic-like plasticity of the primary motor hand area is impaired in focal hand dystonia. Brain 128(8): 1943-1950.

8. Sheehan D, Lecrubier Y, Sheehan KH, Amorim P, Janavs J, et al. (1998) The Mini Internatioanl Neuropsychiatric Interview (M.I.N.I.): the development \& validation of a structured diagnostic psychiatric interview. J Clin Psychiatry 59: 22-33.

9. Burke RE, Fahn S, Marsden CD, Bressman SB, Moskowitz C, et al. (1985) Validity and reliability of a rating scale for the primary torsion dystonias. Neurology 35(1): 73-77.

10. Bohannon R, Smith M (1987) Interrater reliability of a modified Ashworth scale of muscle spasticity. Phys Ther 67(2): 206-227.

11. Jedynak PC, Tranchant C, De Beyl DZ (2001) Prospective clinical study of writer's cramp. Mov Disord 16: 494-499.

12. Xiao J, Zhao Y, Bastian RW, Perlmutter JS, Racette BA, et al. (2010) Novel THAP1 sequence variants in primary dystonia. Neurology 74(3): 229238.

13. Gasser T, Windgassen K, Bereznai B, Kabus C, Ludolph AC, et al. (1998) Phenotypic expression of the DYT1 mutation: a family with writer's cramp of juvenile onset. Ann Neurol 44(1): 126-128.

14. Van Den Bos M, Marotta R, Goldup S, Chataway T, Firgaira F, et al (2004) Writer's cramp in an Australian pedigree with DYT1 dystonia. J Clin Neurosci 11(5): 537-539.

15. Leube B, Rudnicki D, Ratzlaff T, Kessler KR, Benecke R, et al. (1996) Idiopathic torsion dystonia: assignment of a gene to chromosome $18 p$ 
in a German family with adult onset, autosomal dominant inheritance and purely focal distribution. Hum Mol Genet 5(10): 1673-1677.

16. Bhidayasiri R, Jen JC, Baloh RW (2005) Three brothers with a very late onset writer's cramp. Mov Disord 10(20): 1375-1377.

17. Fuchs T, Gavarini S, Saunders-Pullman R, Raymond D, Ehrlich ME, et al. (2009) Mutations in the THAP1 gene are responsible for DYT6 primary torsion dystonia. Nat Genet 41(3): 286-288.

18. Defazio G, Brancati F, Valente EM, Caputo V, Pizzuti A, et al. (2003) Familial blepharospasm is inherited as an autosomal dominant trait and relates to a novel unassigned gene. Mov Disord 18(2): 207-212.

19. Kamm C, Naumann M, Mueller J, Mai N, Riedel L, et al. (2000) The DYT1 GAG deletion is infrequent in sporadic and familial writer's cramp. Mov Disord 15(6): 1238-1241.

20. Leube B, Hendgen T, Kessler KR, Knapp M, Benecke R, et al. (1997) Evidence for DYT7 being a common cause of cervical dystonia (torticollis) in Central Europe. Am J Med Genet 74(5): 529-532.

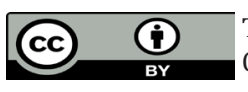

This work is licensed under Creative Commons Attribution 4.0 License

Submission Link: https://biomedres.us/submit-manuscript.php
21. Defazio G, Berardelli A, Hallett M (2007) Do primary adult-onset focal dystonias share aetiological factors? Brain 130(5): 1183-1193.

22. Bentivoglio AR, Ialongo T, Contarino MF, Valente EM, Albanese A, et al. (2004) Phenotypic characterization of DYT13 primary torsion dystonia. Mov Disord 19(2): 200-206.

23. Puschmann A, Xiao J, Bastian RW, Searcy JA, LeDoux MS, et al. (2011) An African-American family with dystonia. Parkinsonism Relat Disord 17(7): 547-550.

24. Gasser T, Bove CM, Ozelius LJ, Hallett M, Charness ME, et al. (1996) Haplotype analysis at the DYT1 locus in Ashkenazi Jewish patients with occupational hand dystonia. Mov Disord 11(2): 163-166.

25. O'Riordan S, Raymond D, Lynch T, Saunders-Pullman R, Bressman SB, et al. (2004) Age at onset as a factor in determining the phenotype of primary torsion dystonia. Neurology 63(8): 1423-1426.

26. Al-Mohaimeed AA, Sharaf FK (2013) Breaking bad news issues: a survey among physicians. Oman Med J 28(1): 20-25.

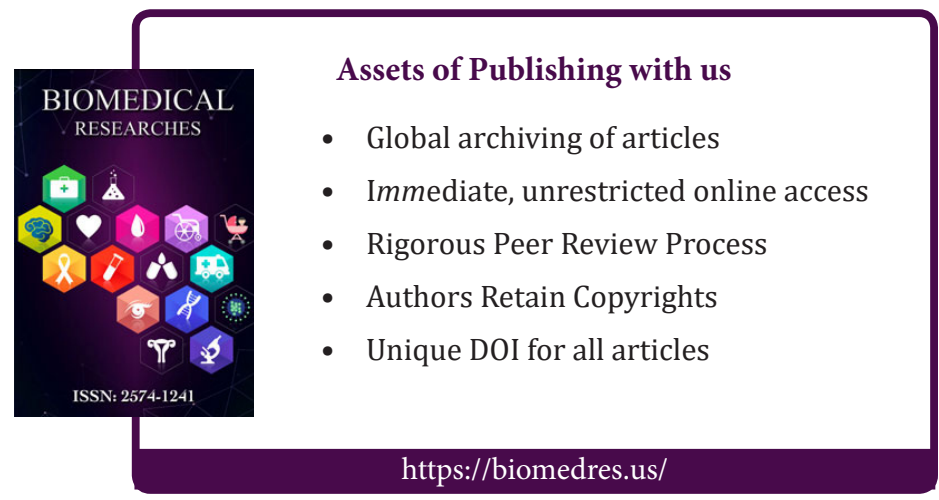

